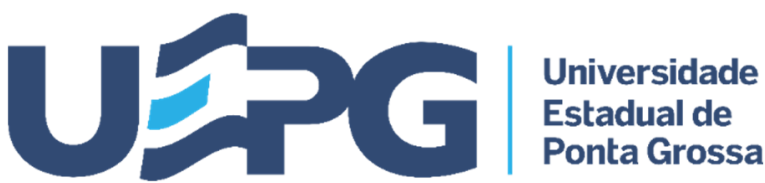

Revista Teias do Conhecimento

Ano 1, Numero 1, 2021

\title{
ESTRANGEIRISMOS NA LINGUAGEM DO COTIDIANO DOS EDUCANDOS DA EJA
}

\author{
http://doi.org/10.5212/RevTeiasConhecimento.v1i1.20210090
}

Rogério Soares Fragoso*

https://orcid.org/0000-0001-8982-4142

http://lattes.cnpq.br/9906677026041676

Sonia Maria Chaves Haracemiv ${ }^{*}$

https://orcid.org/0000-0001-9305-5227

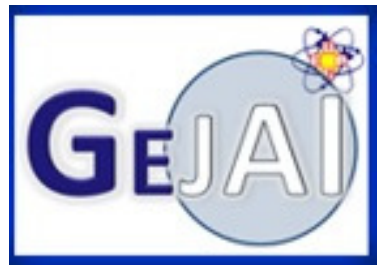

http://lattes.cnpq.br/1257464125778276

RESUMO: Sabe-se que a valorização da linguagem é um dado indiscutível e que a língua, por receber diversas influências, possui um caráter heterogêneo. Por esse motivo, surgem termos estrangeiros na língua falada, permanecendo por muito tempo no uso dos brasileiros. Sentindo a necessidade de descobrir a razão de como a língua estrangeira é tão valorizada e receptiva pelos brasileiros, esse trabalho científico investigou o uso de estrangeirismos, na linguagem do cotidiano dos adultos. O relato de experiência partiu da reflexão sobre como a produção publicitária se apresenta como um possível introdutor de estrangeirismos, tendo como objetivo reconhecer e analisar a presença de palavras e/ou expressões que tem origem na língua estrangeira e que estão presentes na nossa língua materna; discutir em que medida o uso de termos estrangeiros afeta a identidade das pessoas, uma vez que, a língua é um dos aspectos culturais que compõem essa identidade.

PALAVRAS-CHAVE: Estrangeirismos. Linguagens. Cultura. Identidade.

\footnotetext{
* Mestre pela Universidade Federal do Paraná (UFPR) e Professor da Rede Municipal de Educação de Curitiba (Paraná), 圈 profrogeriosoares@yahoo.com.br

** Pós-doutora pela Universidade Federal do Rio de Janeiro (UNIRIO) e Professora do Programa de Pós-Graduação em Educação da Universidade Federal do Paraná (UFPR), 兒 sharacemiv@ufpr.br
} 


\title{
EDUCATION IN THE PROCESS OF RESOCIALIZATION OF THE PENDANT
}

\begin{abstract}
This work presents an exploratory qualiquantitative study that aims to analyze the school evolution of inmates at the State Penitentiary of Maringá (PEM). With regard to the discussions of the educational process constituted within the PEM about what should be the educational role in the resocialization of inmates between the years 2006 to 2010, the analyzes were carried out under a dialectical historical perspective and it was concluded that the increase in the school level is essential for all inmates to get better work opportunities and social inclusion after serving their sentence.
\end{abstract}

KEYWORDS: Education; Penitentiary; Resocialization.

\section{EDUCACIÓN EN EL PROCESO DE RESOCIALIZACIÓN DEL COLGANTE}

RESUMEN: Este trabajo presenta un estudio exploratorio cualitativo que tiene como objetivo analizar la evolución escolar de los internos de la Penitenciaría Estatal de Maringá (PEM). En cuanto a las discusiones del proceso educativo constituido dentro del PEM sobre cuál debe ser el rol educativo en la resocialización de los internos entre los años 2006 a 2010, los análisis se realizaron bajo una perspectiva histórica dialéctica y se concluyó que el incremento de El nivel escolar es fundamental para que todos los reclusos obtengan mejores oportunidades laborales e inclusión social después de cumplir su condena.

PALABRAS CLAVE: Educación; Penitenciario; Resocialización. 


\section{INTRODUÇÃO}

Nesta apresentação encontra-se descrita uma proposta pedagógica de intervenção, como experiência prática de ensino do componente curricular Língua Estrangeira/Inglês, estudantes da Educação de Jovens e Adultos (EJA), na faixa etária de 18 a 29 anos, intitulado: "Estrangeirismos na Linguagem do Cotidiano dos Educandos da EJA". Apresenta-se a área de conhecimento Linguagem e Comunicação, que, de acordo com os Parâmetros Curriculares Nacionais (PCNs) de Língua Estrangeira, no que se refere à perspectiva educacional a aprendizagem:

[...] de Língua Estrangeira contribui para o processo educacional como um todo, indo muito além da aquisição de um conjunto de habilidades linguísticas. Leva a uma nova percepção da natureza da linguagem, aumenta a compreensão de como a linguagem funciona e desenvolve maior consciência do funcionamento da própria língua materna. Ao mesmo tempo, ao promover uma apreciação dos costumes e valores de outras culturas, contribui para desenvolver a percepção da própria cultura por meio da compreensão da(s) cultura(s) estrangeira(s) (BRASIL, 1998, p. 37).

O aprendizado de uma Língua Estrangeira desperta no educando o interesse pelo aprendizado de novas culturas e a compreensão da sua própria. A aprendizagem é, portanto, necessária como instrumento de compreensão do mundo, de inclusão social e valorização pessoal. A proposta curricular para EJA propõe:

[...] a aprendizagem de uma língua estrangeira contribui para a construção da cidadania e favorece a participação social, permitindo que os alunos jovens e adultos ampliem a compreensão do mundo em que vivem, reflitam sobre ela e possam nela intervir. Especificamente no contexto da EJA, o ensino de Língua Estrangeira amplia as possibilidades de ascensão profissional, as opções de lazer, o interesse pela leitura e pela escrita e a percepção da escola como um contexto para a constituição da identidade do aluno (BRASIL, 2002, p. 68).

A partir do que os PCNs pontuam, entende-se que vários elementos se conjugam a fim de dar conta da aprendizagem de uma língua estrangeira. Paulo Freire (1996) corrobora com essa ideia ao afirmar que:

[...] pode-se dizer que um desses fatores é o mais importante: estar motivado para aprender, pois ele constitui a melhor forma de aprendizado, independentemente da metodologia ou abordagem a ser utilizada. Diante das dificuldades do educador, torna-se necessário que o trabalho em sala de aula tenha um encaminhamento mais próximo da realidade dos educandos. É preciso fazer com que os jovens compreendam melhor o mundo que os cerca (p. 89). 
O presente estudo tem como objetivo refletir sobre a influência e a importância da Língua Inglesa no cotidiano dos educandos da Educação de Jovens e Adultos. Aprender uma língua estrangeira nos dias atuais tornou-se essencial, e ensinar um outro idioma para alunos de EJA é um grande desafio para os professores, pois para esses jovens e adultos, o inglês é considerado difícil de entender e falar. Eles consideram o aprendizado algo inatingível e desnecessário para seu dia a dia. Como norteadores da fundamentação e atividades relacionadas foram pesquisados os autores Bentes (2011), Faraco (2001), Freire (2006), Freitas (2001) e Oliveira (2006).

Com base nas Diretrizes do Projeto Pedagógico Integrado (PPI) do Projovem Urbano, escolhe-se o componente curricular Língua Estrangeira/Inglês com 0 conteúdo específico: "Estrangeirismos na Linguagem do Cotidiano dos Educandos da EJA", elencando como objetivos: reconhecer e analisar a presença de palavras e/ou expressões que tem origem na Língua Estrangeira/Inglês e que estão presentes na nossa língua materna; refletir sobre o uso de palavras e/ou expressões estrangeiras usadas no cotidiano das pessoas; discutir em que medida o uso de termos estrangeiros afeta a identidade dos brasileiros, reconhecer marcas ou nomes de produtos escritos em Inglês presentes no dia-a-dia.

A língua, como manifestação de um grupo social, possui um caráter heterogêneo. Por isso, muitos estudiosos têm se dedicado ao estudo das manifestações linguísticas. Este estudo científico preocupou-se com os termos estrangeiros que entram na língua portuguesa e é justificado pelo crescente surgimento desses estrangeirismos no cotidiano da linguagem. Nota-se que essa abertura para o estrangeiro é presente no Brasil, não só em termos linguísticos, mas principalmente em termos culturais.

Historicamente, o uso de estrangeirismos na língua portuguesa ocorreu, em especial no português do Brasil, por empréstimos devido ao contato linguístico, à necessidade de comunicação imediata e devido a uma necessidade de uso e de entendimento. Outros estrangeirismos aparecem na língua falada e permanecem muito tempo no uso dos brasileiros, demonstrando que a língua brasileira não é homogênea, nem pura. Ao analisarmos a questão da linguagem, podemos perceber 
uma diversidade de elementos que não pertencem à língua materna, se incorporando ao vocabulário dos falantes. Fazendo parte desse quadro estão os estrangeirismos, os quais retratam a forte influência exercida por outras culturas, que se manifestam no vestuário, culinária, música, cinema, comportamento, e, sobretudo, na linguagem.

Na visão de Faraco (2001):

Estrangeirismo é o emprego, na língua de uma comunidade, de elementos oriundos de outras línguas. No caso brasileiro, posto simplesmente, seria o uso de palavras e expressões estrangeiras no português. Trata-se de fenômeno constante no contato entre comunidades linguísticas, também chamado de empréstimo (p. 15).

O autor considera que os estrangeirismos atuam como palavras ou expressões de outras línguas, usadas em algumas áreas do nosso cotidiano. Atualmente podemos observar o uso cada vez mais frequente desses estrangeirismos, como fatores decorrentes da globalização e do grande avanço dos recursos tecnológicos.

O emprego de palavras estrangeiras tem se popularizado no cotidiano das pessoas. Tanto na comunicação oral quanto na escrita, é cada vez mais comum se notar palavras de origem inglesa em conversações informais. Tornou-se muito usual ouvirmos as pessoas se utilizarem desse artifício em determinadas situações, tais como: "Vamos salvar isso em um pen drive", "Vamos almoçar em um fast-food", "Vamos ao shopping", entre outros. Os mesmos estão presentes na mídia e na Internet, como também nos nomes de lojas e supermercados, querendo com isso provocar algum tipo de impressão no público-alvo. Salientamos que a circulação de palavras estrangeiras no Brasil vem contribuindo para a ampliação de nosso léxico, e em muitos casos, ampliando semanticamente seus usos. A invasão do estrangeirismo não empobrece a língua, mas sim a enriquece, pois aumenta o léxico. O Brasil sofreu e sofre influências lexicais por meio da música, da cultura, etc. Algumas palavras estão enraizadas em nosso idioma ficando difícil separá-las, isso graças a influências pelas quais passamos. A propósito, Machado de Assis, nosso escritor maior, deixou-nos, já em 1873, a seguinte lição:

Não há dúvida que as línguas se aumentam e alteram com o tempo e as necessidades dos usos e costumes. Querer que a nossa pare no século de quinhentos, é um erro igual ao de afirmar que a sua transplantação para a 
América não the inseriu riquezas novas. A este respeito a influência do povo é decisiva. Há, portanto, certos modos de dizer, locuções novas, que de força entram no domínio do estilo e ganham direito de cidade. (p. 25).

O levantamento de ocorrências de uso de palavras estrangeiras no Português do Brasil foi feito com base em folders de supermercado explorando marcas escritas em Inglês de produtos comercializados. A leitura midiática tem no gênero textual explorado folder, um instrumento didático no processo de ensino e aprendizagem da Língua Inglesa. Através da sua leitura, imagem e palavra, respectivamente, se manifestam mais completas e contextualizadas com situações de prática de linguagem oral e escrita envolvidas no processo de comunicação.

A utilização de propagandas para se analisar e refletir sobre a influência de palavras e expressões em inglês tem a finalidade de motivar a compreensão dos educandos, levando-os ao envolvimento com a aprendizagem, pois se eles encontrarem sentido em aprender, estarão motivados em adquirir o conhecimento. A propaganda será apenas um instrumento no processo de aprendizagem para promover a aproximação dos estudantes com o Inglês.

Hoje acredita-se que o caminho mais seguro é trabalhar a Língua Inglesa a partir do contexto social. Essa ideia foi muito propagada por Paulo Freire (2006), que valorizava a presença do saber das camadas populares na sala de aula, propondo que:

[...] com uma pesquisa prévia do universo dos termos falados pelos educandos no seu contexto social, possam ser selecionados alguns - as chamadas palavras geradoras - para que propiciem a formação de outros e também funcionem como ponto de partida para que a turma compreenda o mundo e organize seu pensamento a respeito dele (p. 80).

Paulo Freire ensinava com palavras vindas do próprio contexto de vida das pessoas. O método de Paulo Freire não ensina a repetição de palavras, mas incentiva o desenvolvimento da capacidade no aluno de pensá-las com base nas palavras retiradas do seu cotidiano. Percebe-se que a preocupação pela realidade é constante. Desta forma, Freire trazia em sua prática de alfabetização tudo que os alunos viam em seu dia a dia, apresentando palavras que continham em seus cotidianos. Por meio da própria realidade das pessoas, conquistou a confiança dos educandos e os fez 
refletir sobre o mundo em que viviam.

Acredita-se que a escola deve trabalhar com o conhecimento do cotidiano, mais próximo da realidade dos educandos que frequentam as escolas. Deve-se ter em mente sempre o objetivo de procurar novos meios de conquistar os educandos e, então, realizar o objetivo de facilitar o aprendizado do novo idioma. Logo, explorar palavras estrangeiras inseridas no cotidiano dos jovens e adultos pode ser um agente facilitador no ensino e aprendizagem dos discentes. Poderá funcionar como instrumento motivador desse meio, despertando o interesse do educando, auxiliandoo na ampliação do seu conhecimento e despertando à vontade em aprender.

As atividades desenvolvidas através das palavras mais conhecidas pelos alunos e também a utilização de propagandas deve proporcionar um ambiente agradável da sala de aula, é algo que eles estão acostumados a ver e ouvir no seu dia a dia. A propaganda pode facilitar a compreensão melhorando o interesse pelo conteúdo trabalhado, quando seu uso for planejado e consciente, levando em consideração que o objetivo maior é a aprendizagem. Através da observação das palavras, da análise e reflexão poderão compreender a importância do estudo da Língua Inglesa, mesmo que ainda não compreendam todas as palavras em sua língua nativa.

\section{COM A PALAVRA O ESPAÇO DO PROJOVEM URBANO}

O Programa Projovem Urbano tratava-se de um programa do Governo Federal que se iniciou durante o ano de 2004 com o Grupo Interministerial da Juventude, para elaborar um diagnóstico sobre a juventude brasileira e mapear as ações governamentais que seriam dirigidas especificamente aos jovens e adultos, tendo em vista a indicação de referências para uma política nacional da juventude. O Grupo Interministerial da Juventude sugeriu a implantação de uma política nacional inovadora para a juventude, que compreendia o Programa Nacional de Inclusão de Jovens: Educação, Qualificação e Participação Cidadã - Projovem Urbano - voltado especificamente para o segmento juvenil mais vulnerável e menos contemplado por políticas públicas vigentes (BRASIL, 2008, p. 21). 
Os núcleos que atendiam o PJU estavam inseridos em escolas da Rede Municipal de Ensino (RME), Secretaria Municipal de Educação (SME), da cidade de Curitiba, Paraná, trabalhando com gestão compartilhada. O programa propunha um trabalho na perspectiva de contribuir especificamente para a reinserção do jovem na escola; a identificação de oportunidades de trabalho e qualificação profissional inicial; a oferta de oportunidades de desenvolvimento de vivências desses jovens e adultos em ações comunitárias e o acesso dos educandos à inclusão digital como instrumento de inserção produtiva e de comunicação.

Apresentar uma proposta diferenciada, organizada de forma diferente da oferecida na chamada "escola regular" ou nas propostas de Educação de Jovens e Adultos (EJA) pela qual eles já passaram, é um processo difícil, mas necessário. Neste contexto, este foi um primeiro passo observado e registrado como boa prática pedagógica: respeitar e partilhar o processo que será vivido por todos como algo novo preservando a individualidade de cada um.

\section{O SABER FAZER PEDAGÓGICO}

A metodologia desenvolvida foi leitura, análise e produção de cartazes explorando o material midiático folder com o intuito de proporcionar a reflexão sobre a influência de Língua Inglesa e estrangeirismos no cotidiano das pessoas. Esta metodologia trabalhou atividades mediadas pelo professor aproximando os educandos desse idioma, buscando contribuir para a sua formação e estímulo para a elaboração da proposta de trabalho com estrangeirismos, tornando a aprendizagem mais significativa e prazerosa no contexto escolar.

A priori o professor instigou os educandos à reflexão de que, sem perceberem, já convivem com a Língua Inglesa, lendo nomes de produtos, ouvindo músicas, observando nomes de estabelecimentos, marcas de roupas, propagandas e em palavras usadas diariamente nos diversos ambientes com os quais interagem. Apresenta-se a seguinte sequência didática:

10 Momento: Problematização: Refletir sobre a influência da Língua inglesa e despertar o interesse para aprendê-la. Como estratégia para sensibilização do 
conteúdo o professor realizou uma sondagem sobre o que os educandos afirmavam saber sobre a Língua Estrangeira, perguntando quem usa facebook, vai ao shopping, já fez download de um filme ou simplesmente já comeu um hot dog. A Figura 1 ilustra o momento em sala de aula.

\section{Figura 1 - Sensibilização para o conteúdo da aula}

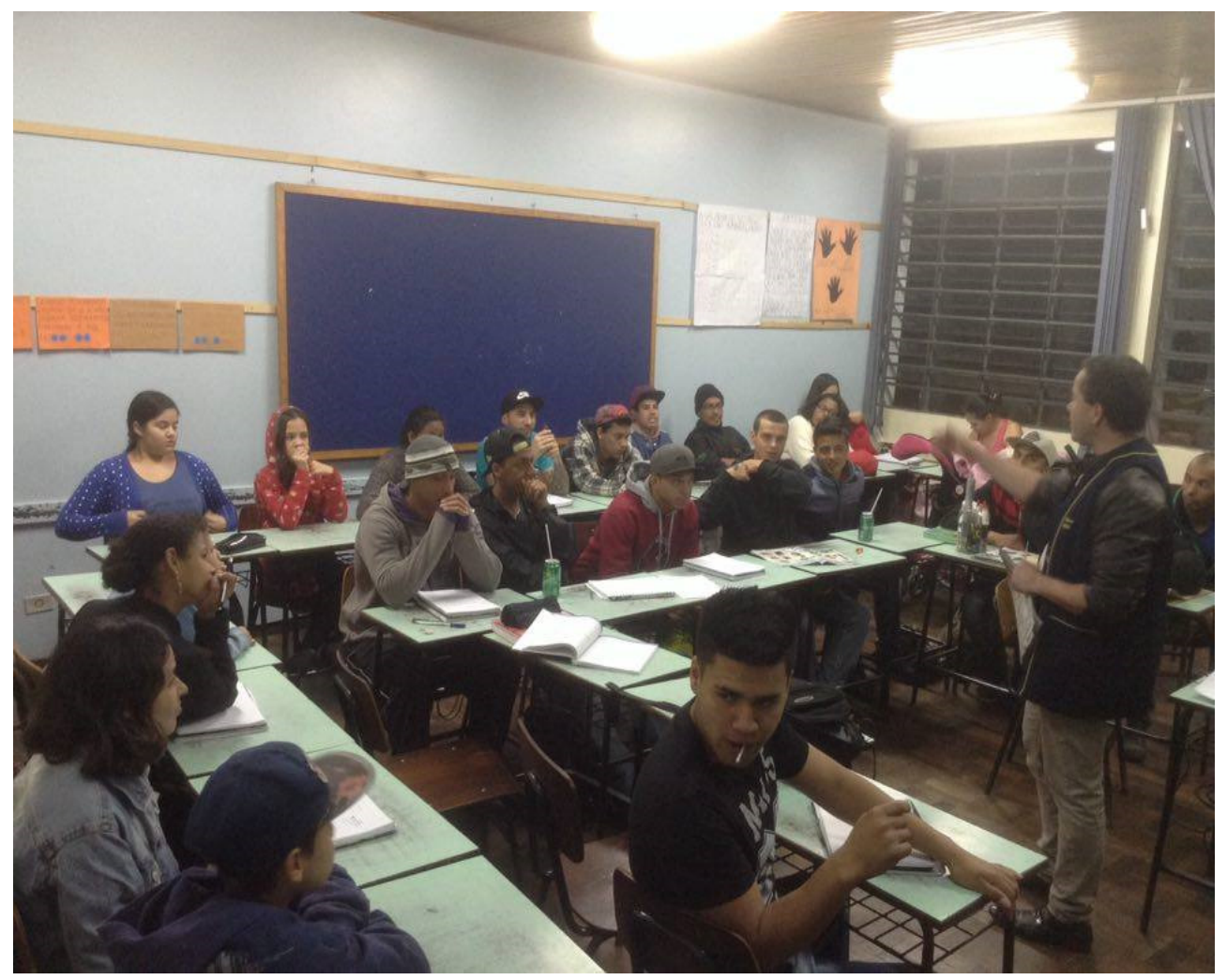

Fonte: Os autores, 2016

Os educandos são jovens e adultos que fazem download de filmes, curtem música de sucesso internacional, acessam páginas da internet. $E$ fazem tudo isso usando, além da língua materna, a língua inglesa. Observa-se que a pluralidade de situações em que se deparam com o uso do Inglês em diversos meios faz com que se ressalte a importância de seu ensino. Segundo o Projeto Político Integrado (PPI) a Língua Estrangeira Moderna/Inglês está:

[...] presente nos lugares mais íntimos, desde etiquetas de roupas a marcas de tênis, ou nos mais visíveis tais como, outdoors, revistas, materiais midiáticos, equipamentos eletrônicos, etc.; além dos documentos oficiais relacionados à área e Educação no Brasil, tais como na LDB (CURITIBA, 
2012, p. 72).

Em linhas gerais, a escolha dos conteúdos da área de conhecimento Língua Estrangeira/Inglês deve:

[...] partir de temas de interesse dos educandos e que possibilitem reflexão sobre sua sociedade e ampliação da visão de mundo, conforme a proposta educativa focalizada neste documento. Nesse sentido, o conteúdo deve ser sempre contextualizado com práticas do dia a dia, colocando o educando para participar mais, trazendo os conteúdos para a sala de forma dinâmica e exigente. Dinâmica no sentido de trabalhar com conteúdos significativos, presentes no cotidiano dos jovens e exigente, no sentido de colocar o educando para falar as palavras em Inglês, praticando a disciplina tanto na sala de aula quanto no quotidiano (CURITIBA, 2012, p. 114).

$2^{\circ}$ Momento: Leitura de texto - foi trabalhado um pequeno texto para situar. $O$ texto trabalhado é: "O cotidiano de Maicon", o qual apresenta no seu contexto, o emprego de diversas palavras estrangeiras. Nessa atividade os educandos poderão refletir e analisar como o inglês está vinculado no nosso dia a dia.

Ao analisar a questão da linguagem neste texto, pode-se perceber uma diversidade de elementos que não pertencem à língua materna, se incorporando ao vocabulário dos falantes. Para Faraco (2001),

Em tempos de desenvolvimento e descobertas científicas, de computadores com internet cada vez mais presentes em nosso dia-a-dia, nada mais comum do que uma avalanche de palavras de outra língua em nosso meio. A esse fato dá-se o nome de Estrangeirismos. Isso nada mais é do que o emprego de termos oriundos de uma comunidade $\mathrm{x}$ em uma comunidade y (p. 110).

3․ Momento: Brainstorming - Nesta etapa os educandos apontaram expressões estrangeiras mais usadas ou vistas no cotidiano, relacionando oralmente palavras em Inglês presentes no texto e outras que conhecem no dia-a-dia, como por exemplo: fast food, lan house, selfie, outdoor, download, pen drive, hamburger, bluetooth, milk shake, notebook, delivery dentre outras. Esta atividade serviu para desmistificar, logo no início da intervenção, o mito de que o Inglês é difícil e impossível de ser aprendido. A Figura 2 ilustra as expressões estrangeiras expressas pelos educandos da turma. 
Figura 2 - Estrangeirismos no cotidiano da EJA

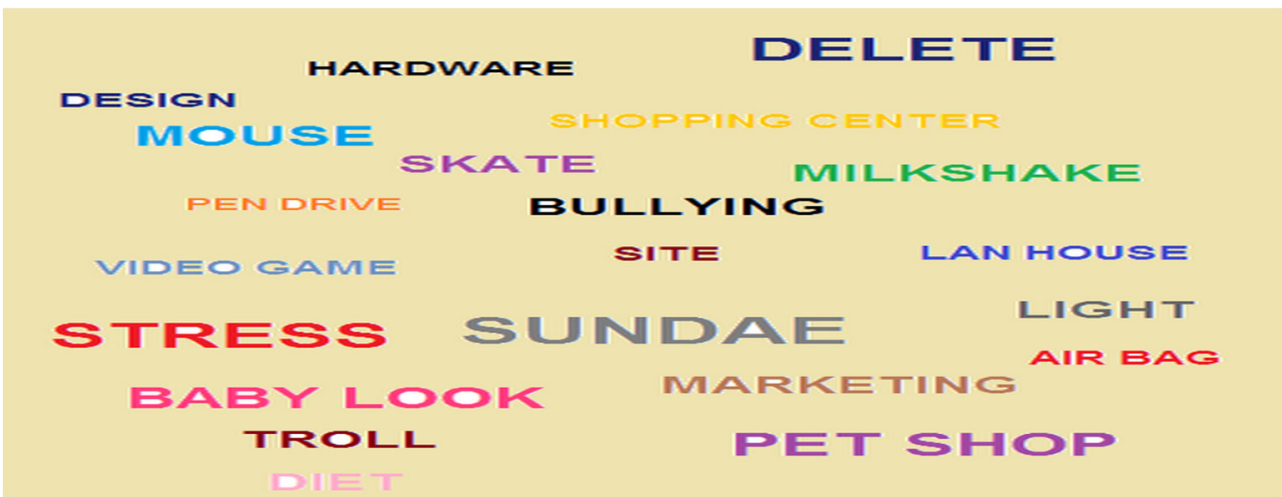

Fonte: Os autores, 2016

Pode ser observado, que as expressões acima foram significadas pelos jovens e adultos presentes no espaço da intervenção, que foi registrada em vídeo.

4. Momento: Escrita das palavras - A medida que os educandos foram falando, 0 professor escreveu no quadro de giz e fez um levantamento dos vocábulos. A intenção desta atividade foi trabalhar com os educandos a Língua Inglesa de forma que percebessem que a mesma não está distante da realidade deles, mas, presente no cotidiano de todos. Na Figura 3 são apresentadas expressões estrangeiras mais usadas pelos educandos.

Figura 3 - Do domínio da oralidade ao domínio da escrita

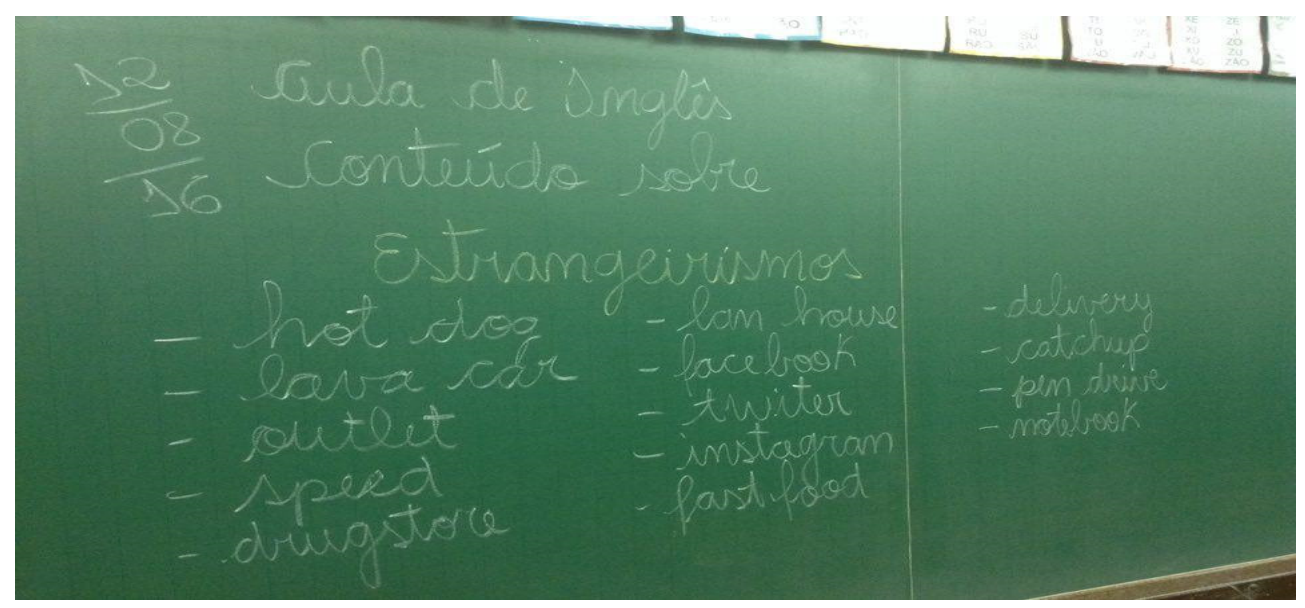

Fonte: Os autores, 2016 
A escrita de palavras estrangeiras tem se popularizado tanto na comunicação oral quanto na escrita, é cada vez mais comum se notar palavras de origem inglesa em conversações informais. De acordo com Bakhtin, na visão de Freitas (2001):

[...] o ensino e aprendizagem de uma língua estrangeira é um processo que sofre influência de vários fatores, dentre eles, podemos mencionar a fala e a escrita. Escrever é a transcrição da língua falada para a escrita, escrever é organizar palavras em texto para comunicar uma mensagem (BAKHTIN, apud FREITAS, 2001, p. 140).

Nesse sentido escrever é um passo muito importante em busca do domínio do idioma. Além de conhecer a pronúncia das palavras, saber escrever ajuda muito no desenvolvimento do vocabulário. A aquisição da escrita em língua estrangeira, através de vocábulos presentes no dia a dia dos jovens e adultos, pode levá-los a se sentirem mais motivados, percebendo que poderão aplicar o que está sendo estudado. Os educandos necessitam ter conhecimento, ainda que prévio da escrita de palavras em Inglês, quer seja para a informação, formação, para o trabalho, para a diversão, etc., tendo como veículo de publicidade a Internet. Sabe-se que a fluência na escrita é difícil de ser atingida, não somente na língua estrangeira, mas também na língua materna. A prática efetiva colabora com o alcance desta fluência.

5․ Momento - Leitura escrita e oral: O professor explicou que, de acordo com as normas gramaticais, quando se emprega palavras e/ou expressões que tem origem em outras línguas denomina-se Estrangeirismos. Para trabalhar o conceito foi apresentado a letra e vídeo da música "Estrangeirismo" (Zé Ramalho); conversando sobre o autor e explorando a oralidade dos educandos.

Observa-se que a oralidade é fator essencial para o processo ensinoaprendizagem da língua estrangeira. Nos PCNs (2012) essa preocupação é expressa quando colocado que:

[...] a oralidade durante as aulas não é observada como algo imprescindível para a aquisição das habilidades linguísticas. Não se pretende desprezar a importância de outras habilidades, porém, espera-se que a oralidade seja trabalhada com a mesma ênfase, a fim de se alcançar uma aprendizagem integral em língua estrangeira (BRASIL, 2012, p. 157). 
Segundo a concepção de Bentes (2011), "[...] deve-se não apenas dar oportunidade aos alunos de observarem e de analisarem determinadas práticas orais, como também deve fornecer os contextos, as motivações e as finalidades para o exercício de diferentes oralidades, na sala de aula e fora dela" (p. 137).

Segundo o autor a oralidade, em sua modalidade de Língua Inglesa, passa precisamente pela tomada de consciência do meio educacional na busca de uma realidade que permita a efetiva construção do conhecimento pela prática, ou seja, se o educando é levado à exposição do uso da língua, consequentemente, a aprendizagem será de maneira prazerosa e consistente, portanto:

Ser exposto à língua em sua modalidade oral se torna de fundamental importância para o aprendizado. Neste contexto, o educador tem papel fundamental no ensino e aprendizagem, que não é apenas o de transmitir conhecimento, mas criar possibilidades para autoprodução ou construção do conhecimento (FREIRE, 1996, p. 142).

Os educandos realizaram uma leitura oral identificando os diversos vocábulos em Inglês apresentados na letra da música.

6‥ Momento - Leitura de imagens - A utilização da leitura de imagens no contexto de ensino de uma língua estrangeira possui uma longa tradição haja visto que estas imagens estão presentes em sala de aula e no livro didático. Vários autores defendem a utilização de imagens para a apreensão de informações e especificamente aprendizado de línguas estrangeiras. A imagem possui várias funções dentro do contexto do ensino de uma língua estrangeira.

A leitura de imagens, o apelo exagerado do não-verbal, no intuito de conseguir a adesão do leitor através do seu poder persuasivo, é fator característico de muitas propagandas apresentadas pela mídia. Percebe-se que isso também vêm permeando o ensino de línguas, seja ela materna ou estrangeira. Nesse contexto, Oliveira (2006) relata que,

Cada vez mais a linguagem escrita, tradicional e linear, comunicadora de práticas sociais através dos mais variados tipos de discurso, cede espaço para o que ela denomina de "mensagem-imagem". É a imagem criando, reproduzindo, comunicando valores, crenças e ideologias (p. 15). 
Para a autora, a tendência cada vez mais orientada para o visual, marca patente da sociedade contemporânea, foi utilizada para incrementar a motivação na aprendizagem da Língua Inglesa.

7ํ Momento - Leitura de material midiático: Para dar início a esta atividade o professor solicitou aos educandos que se organizassem em 6 (seis) equipes. As situações reais de comunicação foram trabalhadas a partir de folders de supermercado, através dos quais, as equipes identificavam, selecionavam e recortavam, marcas escritas em Inglês de produtos comercializados. Em seguida o professor realizou um debate com os educandos sobre as diversas marcas de produtos selecionados escritos na Língua Estrangeira e sua relação com o consumo. Na Figura 4 pode-se verificar o material utilizado.

Figura 4 - Leitura de material midiático: folder

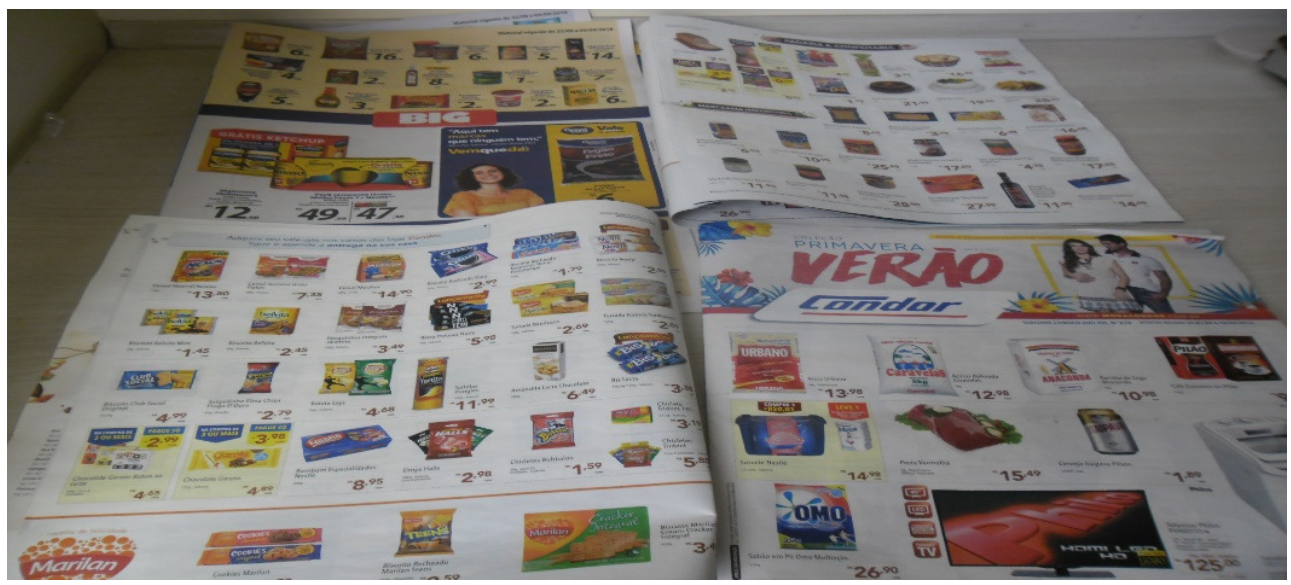

Fonte: Folders de Supermercado, 2016

A escolha do material midiático folder e da metodologia empregada para desenvolver a atividade objetivou oportunizar aos educandos formas de socialização de seus conhecimentos a partir de ações individuais e coletivas. Caracteriza-se pela excepcional praticidade formal e capacidade informativa, o que o torna um dos mais eficientes veículos de comunicação. Com linguagem direta e leitura rápida, preferencialmente ilustrada, seduz por trazer informações objetivas e apresentação gráfica criativa. De acordo com o Dicionário Houaiss da língua portuguesa, folder é um "impresso de pequeno porte, constituído de uma só folha de papel comum com 
uma ou mais dobras, que apresenta conteúdo informativo ou publicitário; folheto" ou ainda "prospecto dobrável". (Dicionário Houaiss, p. 41).

Corroborando a importância do uso do material midiático folder, Freitas (2007) lembra que "o material didático é todo e qualquer recurso utilizado em um procedimento de ensino, visando à estimulação do aluno e à sua aproximação do conteúdo" (p. 21). Nessa concepção:

[...] o professor é o mediador, cuja função é orientar e abrir perspectivas numa relação de troca entre o meio e o aluno, a partir dos conteúdos; e os materiais didáticos devem ser associados à realidade sócio cultural dos educandos tornando a aprendizagem significativa e eficaz. (SILVA, 2009, p. 12).

Como essa estratégia, através do estudo e da produção, o professor propiciou momentos em que os educandos vivenciassem algumas práticas pedagógicas, assim motivando-os a discussões e reflexões. De acordo com Freire (2009, p.118) "[...] falar com clareza sobre o objeto, é incitar o aluno a fim de que ele, com os materiais que ofereço, produza a compreensão do objeto [...]". Pode-se dizer que, por meio do material didático midiático propaganda tanto o educando quanto o educador podem ser protagonistas no desenvolvimento de suas potencialidades.

8․ Momento - Confecção de cartazes: A partir do trabalho com os folders de supermercados foi proposta uma atividade de fixação do conteúdo, pela produção de cartazes ilustrativos com diversas marcas de produtos comercializados escritos na Língua Estrangeira. Em seguida o professor realizou um debate onde foi possível registrar a expressiva participação dos educandos que expuseram os cartazes no mural da escola, com temáticas criada a partir dos produtos selecionados. Também foi confeccionado um cartaz com a letra da música "Estrangeirismo" e a biografia do autor Zé Ramalho. 
As Figuras 5,6,7 e 8 ilustram os trabalhos em equipe e a confecção dos cartazes pelos educandos.

Figura 5

Fonte: Os autores, 2016

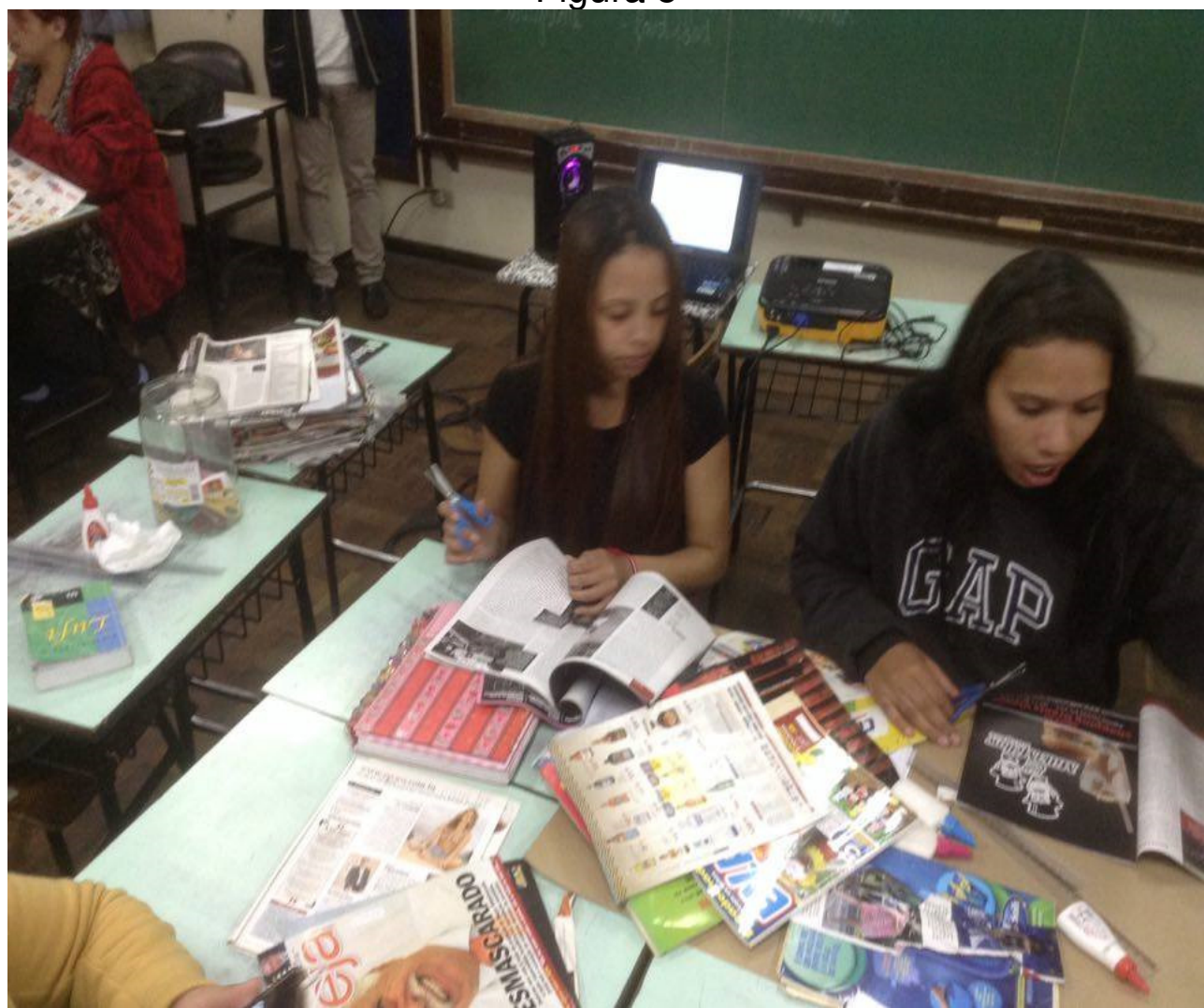

Figura 6

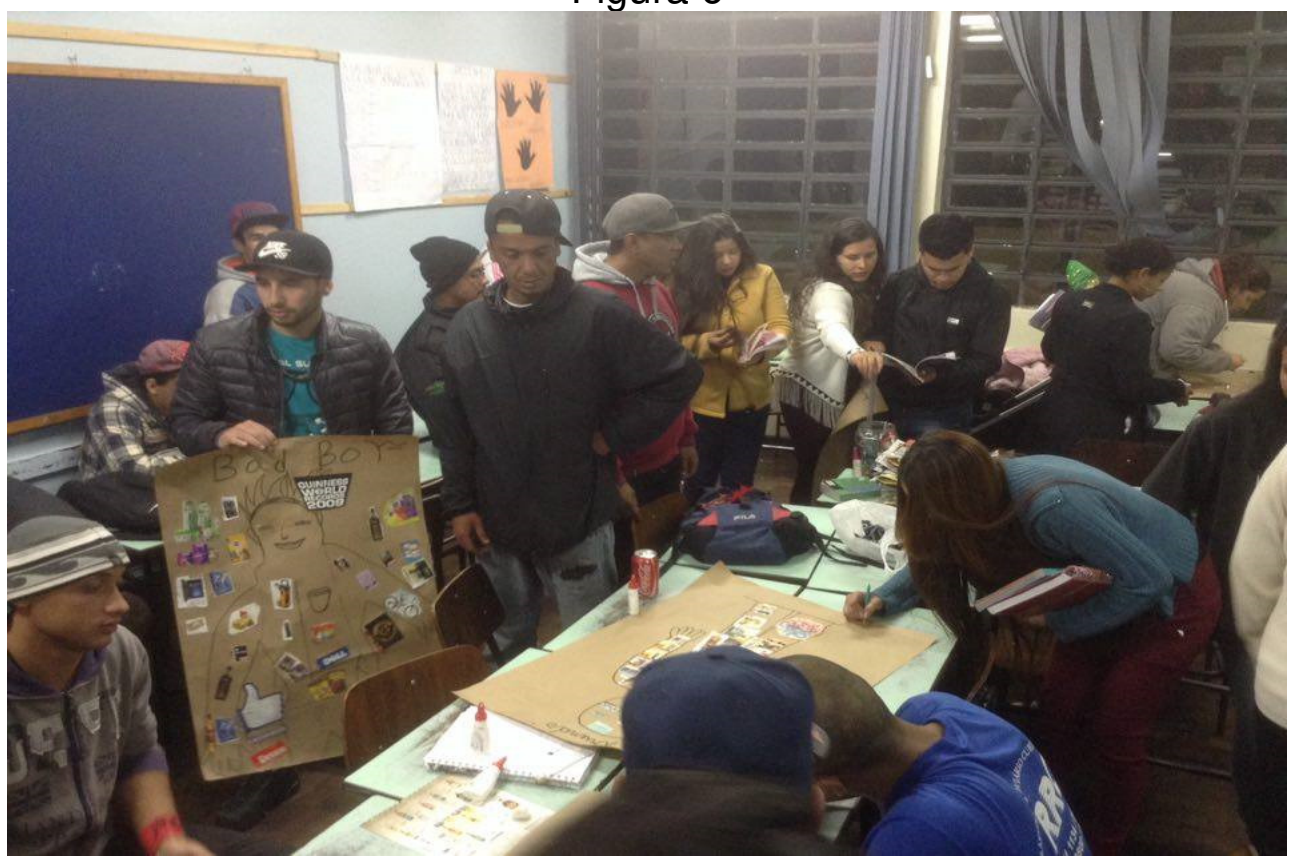

Fonte: Os autores, 2016 


\section{Figura 7}

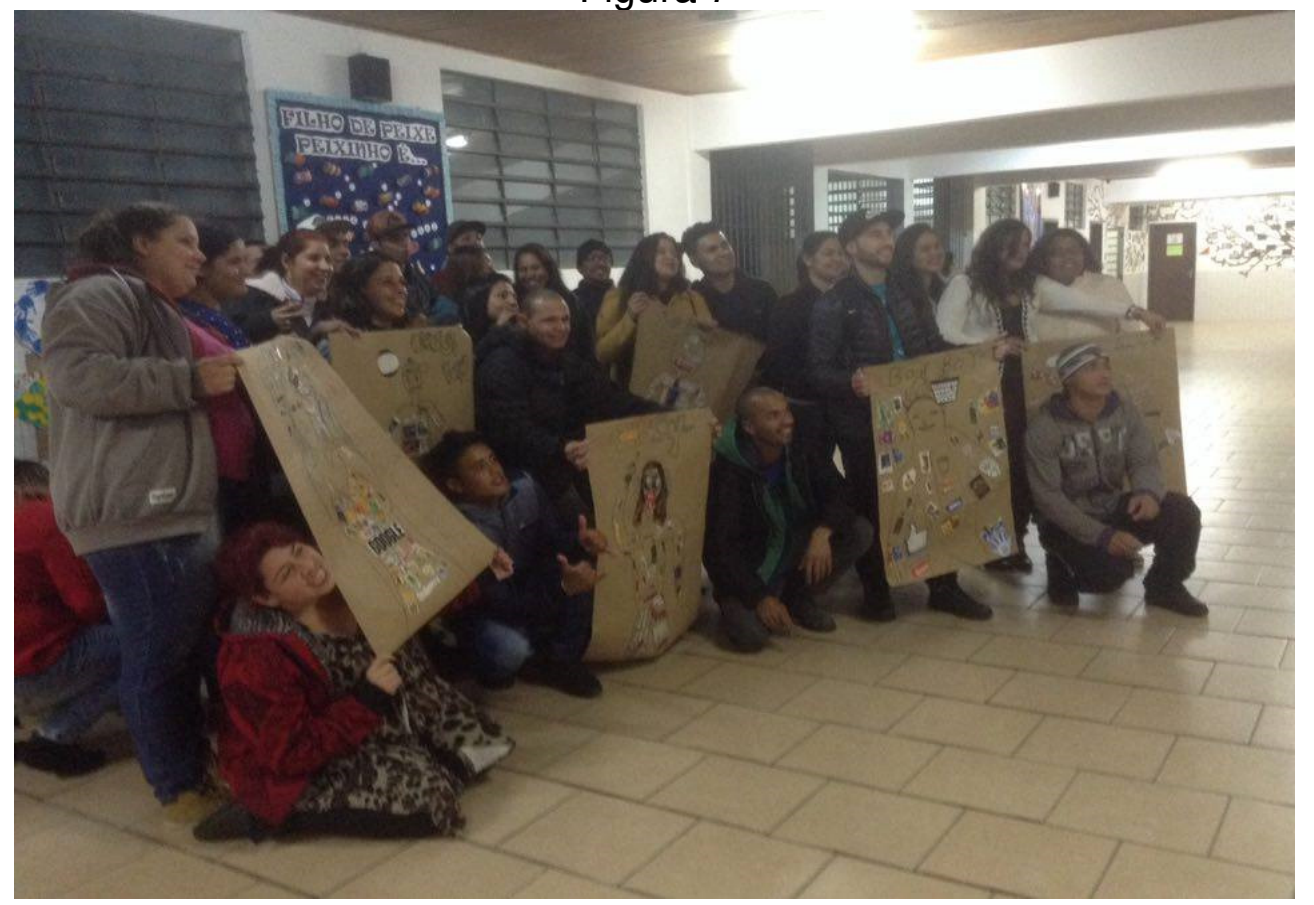

Figura 8

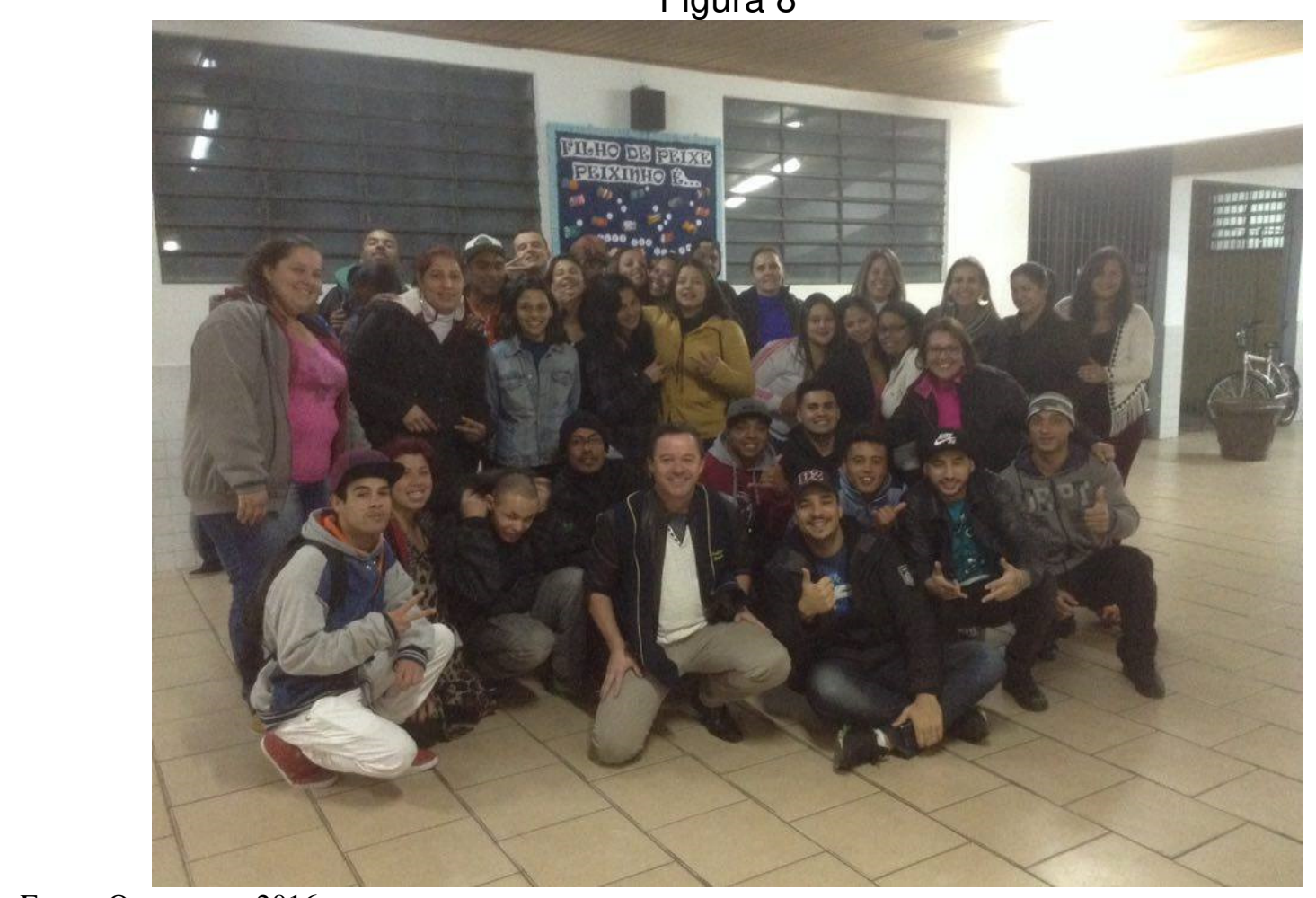

Fonte: Os autores, 2016

O cartaz é uma das atividades desenvolvidas em sala de aula que une 
diferentes habilidades, através do emprego da linguagem mista. Ou seja, o autor pode combinar unidades próprias de diferentes linguagens: linguagem verbal e linguagem não verbal. No contexto escolar, "além de informar e motivar a participação dos alunos, esse recurso possibilita que os mesmos sejam capazes de sintetizar 0 conhecimento construído (FREITAS, 2007, p. 135).

\section{COMO VALIDAR O TRABALHO PROCESSUAL COM ATIVIDADES}

Avaliar o ensino aprendizagem dos alunos atualmente é um grande desafio para os professores. Avaliar sistematicamente cada conhecimento que os alunos vão adquirindo requer do educador práticas, as mesmas as quais é preciso ser elaborada pelo professor com ênfase nas necessidades dos alunos. $O$ docente ao desenvolver o conceito de avaliação contribuirá no processo de aprendizagem dos educandos, julgando cada momento de aprendizagem, orientando-os de maneira a qual todos possam se envolver na sala de aula refletindo sobre os conhecimentos internalizados. Nessa sistematização de situações de aprendizagem afirma SANT'ANA 2005:

\footnotetext{
O professor ao avaliar, deverá ter em vista o desenvolvimento integral do aluno. Assim, comparando os resultados obtidos, ao final, com a sondagem inicial, observando o esforço do aluno de acordo com suas condições permanentes e temporais, constatará o que ele alcançou e quais as suas possibilidades para um trabalho futuro (p. 24).
}

Com o anseio de validar o trabalho foi escolhida a avaliação processual, a qual permitiu que as aprendizagens fossem avaliadas ao longo de todo o processo. A avaliação processual "serve para verificar se o trabalho do professor está sendo produtivo e se os alunos estão de fato aprendendo com as situações didáticas propostas" (WEISZ, 2000, p. 94). Ela indica a prática de examinar a aprendizagem ao longo das atividades realizadas em sala de aula: produções, comentários, apresentações, criações e trabalhos em grupos. Avaliar dessa maneira permitiu acompanhar a construção do conhecimento, identificar eventuais problemas e dificuldades e corrigi-los antes de avançar. Como explica HOFFMANN (2001) "isso ajuda a interpretar o que a turma aprendeu ou não e, assim, intervir, mudando as estratégias".

Partindo desse pressuposto os educandos foram avaliados através da 
participação durante a realização dos trabalhos onde o professor observou o interesse em realizar as tarefas, sendo também fundamental, os diálogos com os alunos e a análise de suas produções. Logo, a avaliação processual revelou-se como um instrumento valioso no processo ensino aprendizagem, possibilitando um possível diagnóstico do educando sobre os conhecimentos adquiridos e propiciando ao educador verificar e refletir a sua prática pedagógica, podendo assim haver uma melhoria no processo de ensino e aprendizagem.

Os relatos escritos e orais desenvolvidos no decorrer das atividades subsidiaram a produção acadêmica desse artigo.

\section{CONSIDERAÇÕES FINAIS}

As reflexões desenvolvidas neste projeto partiram da necessidade de uma visão sobre do uso dos estrangeirismos, buscando uma aproximação com a Língua Inglesa como fator de motivação. Assim, este artigo apresentou os resultados da aplicação de uma proposta pedagógica de intervenção desenvolvida pelos autores e ocorrida em uma escola da Rede Municipal de Ensino, da Secretaria Municipal de Educação, da cidade de Curitiba-Pr, com aplicação de uma aula do componente curricular de Língua Estrangeira/Inglês com conteúdo específico: "Estrangeirismos na Linguagem do Cotidiano dos Educandos da EJA". Essa intervenção pedagógica revelou que a receptividade e a aplicação foram exitosas com o objetivo do projeto alcançado. Os educandos chegaram, ao final da aula, ainda empolgados com estudo de Língua Estrangeira/Inglês e com ótimo aproveitamento do que foi trabalhado. Ressalta-se que a execução das atividades teve a utilização do recurso midiático/folder o que possibilitou maior interação por parte dos educandos por tratarse de algo dinâmico e comum a sua vivência diária.

Constatamos que a utilização do gênero midiático folder constituiu um importante instrumento para o ensino de estrangeirismos na linguagem do cotidiano dos educandos da EJA, por ser um gênero textual multifuncional, portador de valores, prestar-se ao serviço de diversas atividades sócio comunicativas, ao estabelecimento de habilidades de leitura e senso crítico no leitor e a integração de signos verbais e 
imagens, os quais, são permeados de estratégias de persuasão, que na maioria das vezes, passam despercebidas pelo leitor. De acordo com BUCCI (2000), "é uma forma de discurso, organizado para ser informativo e persuasivo, causando grande efeito na formulação de ideologias de consumo" (p. 78). O autor classifica o poder da mídia para a publicidade em três níveis: o cognitivo, que compreende o sentido da mensagem, o interativo, que engloba a relação entre indivíduos, estabelecendo trocas, e a passional, que envolve a sensibilização do receptor.

Logo, os educandos da EJA refletiram que o material explorado se mostrou como um recurso de publicidade que possui seu centro de prioridade no consumidor, utilizando meios que o levem a ações positivas em relação ao produto, serviço ou marca. Assim, seduz o potencial consumidor, até convencê-lo a efetivar uma atitude positiva em relação ao produto ou serviço.

O uso do folder mostrou-se como um material apropriado para as aulas de Língua Inglesa, pois, através dele, a língua pode ser estudada, não por si mesma, como um sistema fechado, mas em seu contexto de uso, onde os educandos refletiram que, o uso de estrangeirismos, principalmente em anúncios publicitários acabam por dar ênfase ao texto e enriquecer o discurso através do qual convence o leitor a optar por um produto ou marca.

O uso dessas palavras estrangeiras faz parte da evolução de toda língua, e isto é um fato tão comum que, consequentemente, algumas palavras vão evoluindo e não percebemos. De acordo com BAGNO (2002) é de salientar que "os estrangeirismos só vêm a enriquecer o vocabulário de uma língua (p. 34)". Nesse contexto, Faraco (2001) declara que: "os estrangeirismos não alteram as estruturas da língua, a sua gramática. Os estrangeirismos contribuem apenas no nível mais superficial da língua que é o léxico" (p. 25).

Percebeu-se que os vocábulos de Língua Inglesa estão inseridos na Língua Portuguesa, através destas palavras tão utilizadas pelos brasileiros, algumas sem necessidade, outras por não haver na Língua Portuguesa um termo que as defina melhor. 
Conclui-se, portanto, que houve êxito na intervenção proposta pois ampliou a visão do aluno em relação da proximidade do Inglês, no seu dia-a-dia. Ressaltou-se a importância de se saber outro idioma e a noção do inglês como língua internacional, tão essencial para o mundo globalizado. Admitimos que a presente proposta de intervenção esteja longe de trazer uma verdade completa sobre o assunto. $\mathrm{Na}$ verdade, se pretendeu apresentar o processo natural de adoção dos estrangeirismos e que esses termos não devem ser analisados como prejuízo à cultura ou a língua, mas como algo próprio da fala. 
Estrangeirismos na linguagem do cotidiano dos educandos da EJA

Rogério Soares Fragoso e Sonia Maria Chaves Haracemiv

\section{REFERÊNCIAS}

BAGNO, Marcos. Preconceito linguístico: o que é, como se faz. São Paulo: Loyola, 2002.

BENTES, Anna Christina. Oralidade, política e direitos humanos. São Paulo: Contexto, 2011.

BUCCI, Eugênio. Sobre ética e imprensa. São Paulo: Companhia das Letras, 2000.

CUNHA, Celso. Língua Portuguesa e Realidade Brasileira. Rio de Janeiro: Edições Tempo Brasileiro, 1981.

CURITIBA. Resolução e Diretrizes Curriculares para Educação de Jovens e Adultos. Prefeitura Municipal de Curitiba, Secretaria Municipal da Educação, Gerência de Educação de Jovens e Adultos. Curitiba, 2012.

DICIONÁRIO HOUAISS. Editora Objetiva. Rio de Janeiro, 2005.

FARACO, Carlos Alberto (org.) Estrangeirismos: uma guerra em torno da língua. São Paulo: Parábola, 2001.

FREIRE, Paulo. Pedagogia da autonomia saberes necessários à prática educativa. 39. ed. São Paulo: Paz e Terra, 2009.

FREITAS, Maria Tereza de Assunção. Bakhtin e a Psicologia. In: FARACO, Carlos Alberto (et al.). 3 ed. Curitiba: Editora da UFPR, 2001.

FREITAS, Olga. Equipamentos e materiais didáticos. Brasília: Universidade de Brasília, 2007.

HOFFMANN, Jussara. Avaliação Mediadora: Uma Prática em Construção da Pré-Escola à Universidade. São Paulo, Mediação, 2001.

OLIVEIRA, Sara. Texto visual e leitura crítica. Pelotas: Linguagem e Ensino, 2006.

SANT’ANA, Ilza Martins. Por que avaliar? Como avaliar? Petrópolis, RJ: Vozes, 2005.

SILVA, Evellyn Ledur da. As tendências pedagógicas e a utilização dos materiais didáticos no processo de ensino e aprendizagem. São Paulo: UNICAMP, 2009.

WEISZ, T. O diálogo entre o ensino e a aprendizagem. São Paulo: Editora Ática, 2000. 